\title{
Aesthetic perceptions and social judgments about different enamel opacities
}

Fernanda Mafei Felix da SILVA ${ }^{(a)}$ Marcela Baraúna MAGNO(a)

Aline Borburema NEVES(a)

Raildo da Silva COQUEIRO(b)

Marcelo de Castro COSTA(a) iD

Lucianne Cople MAIA(a)

Matheus Melo PITHON(a) ID

(a) Universidade Federal do Rio de Janeiro UFRJ, School of Dentistry, Department of Pediatric Dentistry and Orthodontics, Rio de Janeiro, RJ, Brazil.

(b) Universidade Estadual do Sudoeste da Bahia - UESB, Center for Studies in Aging, Candeias, BA, Brazil.

Declaration of Interests: The authors certify that they have no commercial or associative interest that represents a conflict of interest in connection with the manuscript.

\section{Corresponding Author:}

Matheus Melo Pithon

E-mailmatheuspithon@gmail.com

https://doi.org/10.1590/1807-3107bor-2020.vol34.0049

Submitted: December 30, 2019

Accepted for publication: March 24, 2020

Last revision: April 28, 2020
Abstract: This study aimed to evaluate adolescents' aesthetic perceptions and their social judgments regarding different enamel opacities. Sample size was calculated and resulted in the inclusion of 100 adolescents (aged 10 to 15 years) from a public school in Jequié, Bahia, Brazil. Images of enamel opacities were manipulated to create aesthetic enamel defects, such as enamel color changes (unilateral and bilateral white opacity, unilateral and bilateral yellowish opacity, and unilateral and bilateral yellowish opacity with loss of structure). The images of the opacities were based on Fédération Dentaire Internationale's Developmental Defects of Enamel (DDE) Index. Aesthetic perception and social judgments were evaluated using a validated questionnaire with 12 questions (six positive and six negative points) on social aspects, considering the six manipulated images and the control. The photographic analyses were projected one-by-one by computer to adolescents individually in a classroom. Participants had one minute to observe each image and answer the questionnaire. The data were analyzed by descriptions, and the Friedman Wilcoxon test $(p<0.05)$. The results indicate that all opacities negatively impacted social judgment $(p<0.001)$. The enamel aesthetic defects most affecting an individual's perception were bilateral yellow opacity with or without loss of structure $(\mathrm{p}<0.001)$. Regarding social judgment, all participants showed a negative perception of all the tested opacity types $(p<0.001)$. In conclusion, even opacities presenting only a color change caused aesthetic dissatisfaction to the individuals and changes in their social judgment toward others. Color changes in dental enamel have several aesthetic consequences.

Keywords: Child; Esthetics; Dental Enamel Hypoplasia.

\section{Introduction}

Over the years, aesthetic demands have increased mainly in relation to aspects of the smile, ${ }^{1}$ and especially to the presence of developmental defects of enamel (DDE). ${ }^{2,3}$ These have been defined as qualitative or quantitative defects that occur during the phases of amelogenesis. ${ }^{3}$ The most prevalent DDEs are hypomineralization followed by hypoplasia. ${ }^{3}$ The prevalence of these conditions varies considerably and ranges from $6.7 \%$ to $67.1 \%{ }^{4,5,6}$ In relation to etiology, DDEs are associated with prenatal and postnatal aspects (disturbances during pregnancy, 
severe infections and frequent use of antibiotics in childhood) $)^{7,8}$ and genetic mutations in genes responsible for enamel formation. ${ }^{9}$

One of the main characteristics of DDE is discoloration, which may vary from white/yellowish to brown. ${ }^{3,10}$ Another aspect is the loss of tooth structure. This leads to sensitivity and aesthetic problems for the individual, which may affect quality of life..$^{10,11}$ Recent studies have shown interest in knowing not only the opinion of the individual about his physical appearance, but also his social judgment of others' appearance. ${ }^{12,13}$ The social judgment theory applies to the analysis of interpersonal conflicts caused by cognitive differences between individuals. ${ }^{14}$ Sometimes, we are judged by our physical looks, including weight, height and dentofacial esthetics. ${ }^{2}$ Physical appearance may influence how people feel about themselves, and may impact how they are judged by others, especially in adolescent groups that are undergoing physiological and physical changes. ${ }^{15}$

Malocclusions, dental traumas and dental enamel disturbances may be judged negatively not just by the individual who has them, but also and even more by others. ${ }^{16,17}$ Enamel defects have been widely discussed, mainly in terms of color and loss of structure. These defects may affect an individual's social life and self-esteem. ${ }^{18}$ It is important to understand how the impact of dental defects can influence a patient's life, since this information serves to draft public health policies that can prioritize treatment and improve the individual's self-esteem. Thus, the aim of this study was to evaluate adolescents' aesthetic perceptions and their social judgments regarding different enamel opacities.

\section{Methodology}

\section{Ethical aspects and sample}

This study was approved by the local ethics committee under number 0154.0.454.000-11. All subjects/caregivers read and signed a written informed consent form before participating in the study.

The sample size was calculated using $G$ * Power (Version 3.1.9.2, Germany). The analysis of variance of repeated measures considered the following parameters: effect size $f=0.25$ (mean effect size), $\alpha=0.05$, power $=0.80$, and number of measurements $=7$ (control, unilateral white opacity, bilateral white opacity, unilateral yellow opacity, bilateral yellow opacity, unilateral yellow opacity with loss of structure, and bilateral yellow opacity with loss of structure). Pearson's correlation coefficient among repeated measures was 0.20 , and nonsphericity correction, 0.25 . The minimum sample was estimated at 83 individuals. Considering the $15 \%$ required for the statistical tests, the minimum sample size was 95 individuals for the present study. Our study used a final sample of 100 individuals, considering possible use of questionnaires, albeit possibly missing some type of information.

The inclusion criteria were adolescents, boys and girls, ranging in age from 10 to 15 years, regularly enrolled in the public school selected for the study. Individuals who did not have a written informed consent to participate in the study were excluded. The final sample comprised 100 adolescents between 10 and 15 years old, of both sexes, and from a public school of Jequié City, Bahia, Brazil. The participants were invited to answer a questionnaire about their perceptions and judgments regarding different enamel opacities.

\section{Image selection}

A total of 12 images, six from each individual (boy and girl) were manipulated based on healthy enamel to create the effect of enamel color change (ECC). The adolescents (boys and girls) were selected according their age. A boy and a girl at $12.5 \pm 1.2$ years (mean age of the individuals included in the present study - 10 to 15 years old) and the image modification were selected according to DDEs, based on the Fédération Dentaire Internationale's recommended index. ${ }^{3}$ Demarcated opacity without any loss of structure was considered mild, whereas opacities with loss of structure were considered severe cases.

In addition, an image without any enamel alteration was used as a control for all the images. The photographs of the boy and the girl were manipulated to eliminate any malocclusion, and simulate satisfactory aesthetic occlusion. After this step, localized color changes were made to simulate different opacities. ${ }^{3}$ All image alterations were made 
using a software program (Photoshop, CS3, Adobe Systems, San Jose, CA), and the color changes were made only on a central incisor tooth. The modified photographic analyses were designed individually for the adolescents. The images selected were those of unilateral white opacity (Figures 1A, 2A), bilateral white opacity (Figures 1B, 2B) unilateral yellowish opacity (Figures 1C, 2C), bilateral yellowish opacity (Figures 1D, 2D), unilateral yellowish opacity with loss of structure (Figures 1E, 2E), and bilateral yellow opacity with loss of structure (Figures 1F, 2F). Lifesize images were shown, as if the person was there, in a 42", high-resolution monitor. The images were analyzed at an average distance of $50 \mathrm{~cm}$, simulating a casual conversation. The adolescents were given one minute to observe each image and to answer the questions. During their analyses, the adolescents could not use a magnifying glass or any other tool that could modify the design..$^{16}$ The adolescents were also not allowed to return to previous images to make comparisons or alter their initial responses ${ }^{16}$

\section{Questionnaire}

A perception survey was carried out using a questionnaire for individuals between 10 and 15 years old. ${ }^{16}$ This instrument was composed of 12 questions (Table 1) that identified the perceptions of different dental consequences and their influence on social judgments (positive or negative). ${ }^{16}$

The responses were presented in the form of multiple-choice options, each question having four optional answers: the positive characteristics (questions 1 to 6) were coded as "certainly yes" = 3 points, "maybe yes" = 2 points, "maybe not" $=1$ point, and "certainly not" $=0$ points; the negative characteristics (questions 7 to 12) had inverted negative scores for "certainly yes" $=-3$ points, "maybe yes" $=-2$ points, "maybe not" $=-1$ point, and "certainly not" $=0$ points. ${ }^{16}$ The scale gradations ranged from the worst condition (0) to the best possible condition (18) for positive characteristics, and in inverse order for negative characteristics, -18 was the worst, and 0 was the best ${ }^{16}$. The total score could range from 0 to
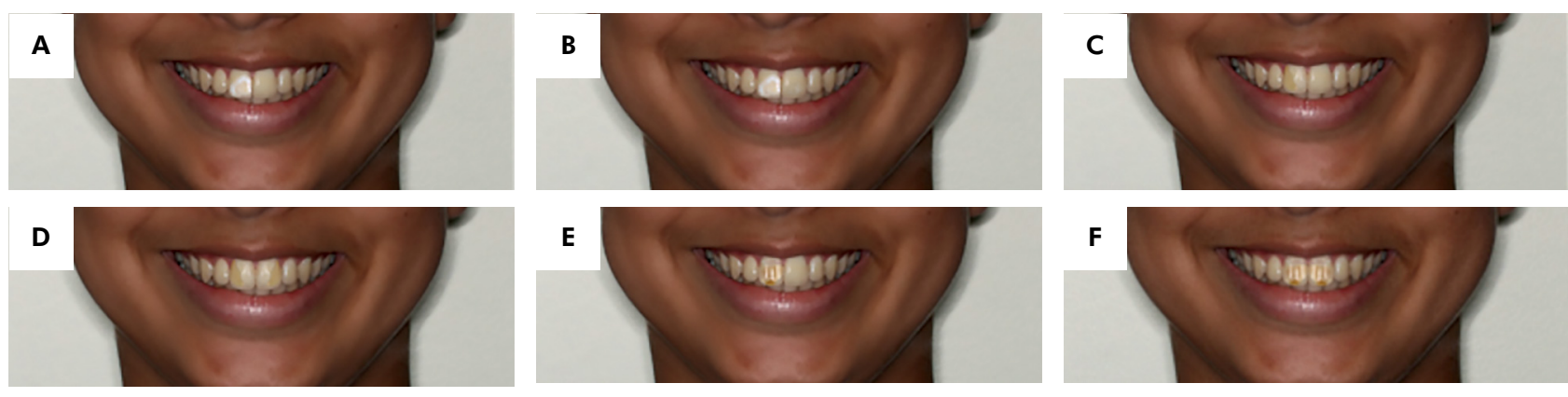

Figure 1. Opacity in the boy: A) Unilateral white opacity; B) Bilateral white opacity; C) Unilateral yellowish opacity; D) Bilateral yellowish opacity; E) Unilateral yellowish opacity + Enamel with loss of structure; F) Bilateral yellowish opacity + Enamel with loss of structure.
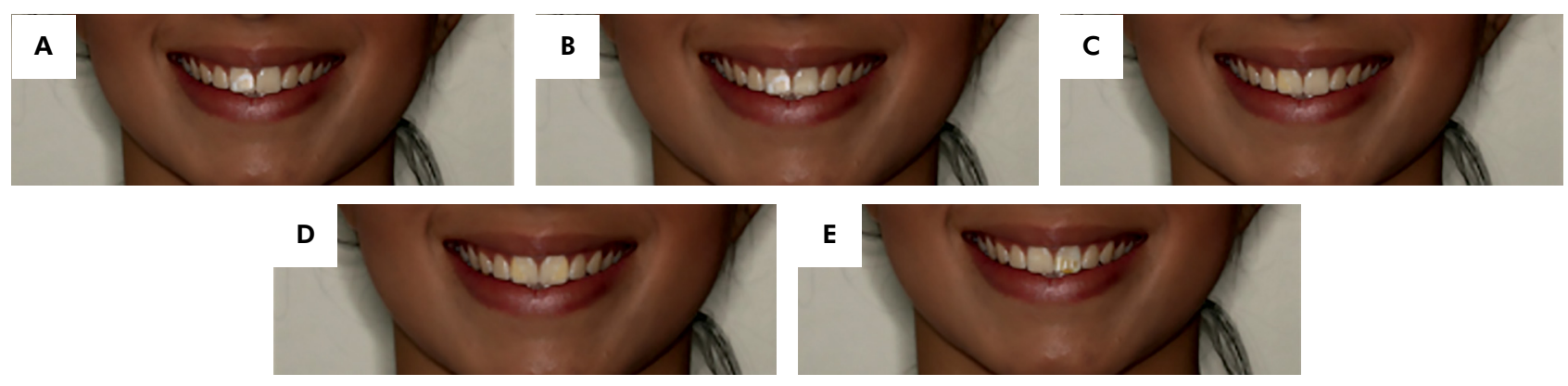

Figure 2. Opacity in the boy: A) Unilateral white opacity; B) Bilateral white opacity; C) Unilateral yellowish opacity; D) Bilateral yellowish opacity; E) Unilateral yellowish opacity + Enamel with loss of structure; F) Bilateral yellowish opacity + Enamel with loss of structure. 
Table 1. Analysis of floor and ceiling effects of social judgment scale.

\begin{tabular}{lcc}
\hline Factor & Floor (\%) & Ceiling (\%) \\
\hline Positive social characteristics & & \\
Control & 0.0 & 20.0 \\
Unilateral white opacity & 0.0 & 0.0 \\
Bilateral white opacity & 0.0 & 0.0 \\
Unilateral yellowish opacity & 0.0 & 0.0 \\
Bilateral yellowish opacity & 0.0 & 0.0 \\
Unilateral yellowish opacity $+{ }^{*} \mathrm{LS}$ & 0.0 & 0.0 \\
Bilateral yellowish opacity $+{ }^{*} \mathrm{LS}$ & 0.0 & 0.0 \\
Negative social characteristics & & \\
Control & 0.0 & 0.0 \\
Unilateral white opacity & 0.0 & 0.0 \\
Bilateral white opacity & 0.0 & 0.0 \\
Unilateral yellowish opacity & 0.0 & 0.0 \\
Bilateral yellowish opacity & 0.0 & 0.0 \\
Unilateral yellowish opacity $+{ }^{*} \mathrm{LS}$ & 0.0 & 0.0 \\
Bilateral yellowish opacity $+{ }^{*} \mathrm{LS}$ & 0.0 & 0.0 \\
Social judgment score & & 0.0 \\
Control & 0.0 & 0.0 \\
Unilateral white opacity & 0.0 & 0.0 \\
Bilateral white opacity & 0.0 & 0.0 \\
Unilateral yellowish opacity & 0.0 & 0.0 \\
Bilateral yellowish opacity & & \\
Unilateral yellowish opacity $+{ }^{*} \mathrm{LS}$ & 0.0 \\
Bilateral yellowish opacity $+{ }^{*} \mathrm{LS}$ & 0.0 \\
\hline
\end{tabular}

18 points for positive characteristics, and from 0 to -18 for negative characteristics. ${ }^{16}$

\section{Validation of the questionnaire}

Before the questionnaire was applied, it was validated, based on a previous study. ${ }^{16}$ The validation process was carried out at two different times, with an interval of 20 days between the two applications. A total of 15 children and adolescents between 10 and 15 years of age participated in this stage. These groups were not included in the final sample.

\section{Statistical analysis}

Acceptability of the instrument was investigated by applying floor and ceiling effects and by analyzing the frequency of responses to each item. The floor effect occurs when more than $15 \%$ of the answers are concentrated on the minimum value, and the ceiling effect occurs at the maximum value of the scales. The construct validity was based on the discriminant validity determined by comparing the control image with the images of the different types of dental enamel opacities using the Friedman test, with comparisons between the pairs tested. ${ }^{19}$

Regarding reliability assessment, the diversity scale considered Cronbach's alpha values $\geq 0.7$, with tolerance for values slightly below this cut-off point. Regarding temporal stability, ICC values $>0.70$ indicated acceptable reproducibility. ${ }^{20}$

The data were analyzed using BioEstat statistical software version 5.0 (Belém, PA, Brazil). Descriptive statistics were performed to express the results as means, medians, standard deviations, interquartile amplitudes, and minimum and maximum values. The effect of dental opacity on perception and social judgment (positive/negative) was evaluated using the Friedman test (with comparisons between pairs made by the Wilcoxon test) at a significance level of $5 \%(\alpha=0.05)$.

\section{Results}

\section{Questionnaire validation process}

\section{Floor and ceiling effects}

All of the 12 questions in the questionnaire showed a 100\% response rate in both the test and the retest, thus indicating high acceptability of the instrument. Although the floor effect was not applied, the ceiling effect was observed for the control image only when positive characteristics were evaluated (Table 1).

\section{Discriminant construct validity}

Discriminant construct validity showed that there was a significant difference $(p<0.05)$ between the control image and all the types of dental enamel opacities (Table 2).

\section{Test-retest}

Satisfactory indexes of agreement were found between the test and the retest results, as evidenced by the intraclass correlation coefficients (Table 3).

\section{Main study results}

A total of 100 adolescents between 10 and 15 years old, of both sexes ( 50 boys and 50 girls) were included in the study, for an average age of $12.5 \pm 1.2$. 
Table 2. Analysis of the Discriminant Construct Validity of the social judgment scale.

\begin{tabular}{lccc}
\hline Type of enamel opacity & Positive social characteristics & Negative Social characteristics & Social judgment score \\
\hline Control & $15.0 \pm 4.0$ & $-4.0 \pm 3.0$ & $11.0 \pm 4.0$ \\
Unilateral white opacity & $11.5 \pm 2.5^{* * *}$ & $-9.0 \pm 2.5^{* * *}$ & $2.0 \pm 3.0^{* * *}$ \\
Bilateral White opacity & $7.0 \pm 6.0^{* * *}$ & $-14.0 \pm 6.0^{* * *}$ & $-5.0 \pm 7.0^{* * *}$ \\
Unilateral yellowish opacity & $12.5 \pm 5.2^{\cdots *}$ & $-12.0 \pm 2.0^{* * *}$ & $-0.5 \pm 4.8^{\cdots *}$ \\
Bilateral yellowish opacity & $7.0 \pm 6.0^{* * *}$ & $-15.0 \pm 3.0^{* * *}$ & $-5.0 \pm 6.0^{* * *}$ \\
Unilateral yellowish opacity $+{ }^{*} \mathrm{LS}$ & $10.0 \pm 3.0^{* * *}$ & $-11.0 \pm 1.5^{* * *}$ & $-0.5 \pm 4.5^{* * *}$ \\
Bilateral Yellowish opacity $+{ }^{*} \mathrm{LS}$ & $7.0 \pm 6.0^{* * *}$ & $-14.0 \pm 0.0^{* * *}$ & $-7.0 \pm 6.0^{* * *}$ \\
${ }^{* *}$ p-valor & $<0.001$ & $<0.001$ & $<0.001$ \\
\hline
\end{tabular}

*LS Loss of structure; ${ }^{* *}$ Friedman's test; ${ }^{* * *}$ indicates significant difference in relation to the control image (Wilcoxon test).

Table 3. Internal consistency measures of the social judgment scale in adolescents.

\begin{tabular}{|c|c|c|}
\hline Factor & $\begin{array}{c}\text { Number of } \\
\text { items }\end{array}$ & $\begin{array}{c}\text { Cronbach's } \\
\text { alpha* }\end{array}$ \\
\hline \multicolumn{3}{|l|}{ Positive social characteristics } \\
\hline Control & \multirow{7}{*}{6} & 0.9 \\
\hline Unilateral white opacity & & 0.9 \\
\hline Bilateral white opacity & & 0.9 \\
\hline Unilateral yellowish opacity & & 0.9 \\
\hline Bilateral yellowish opacity & & 0.9 \\
\hline Unilateral yellowish opacity + LS* & & 0.9 \\
\hline Bilateral yellowish opacity + LS* & & 0.8 \\
\hline \multicolumn{3}{|l|}{ Negative social characteristics } \\
\hline Control & \multirow{7}{*}{6} & 0.9 \\
\hline Unilateral white opacity & & 0.9 \\
\hline Bilateral white opacity & & 0.9 \\
\hline Unilateral yellowish opacity & & 0.6 \\
\hline Bilateral yellowish opacity & & 0.8 \\
\hline Unilateral yellowish opacity + LS* & & 0.7 \\
\hline Bilateral yellowish opacity + LS* & & 0.7 \\
\hline \multicolumn{3}{|l|}{ Social judgment score } \\
\hline Control & \multirow{7}{*}{12} & 0.9 \\
\hline Unilateral white opacity & & 0.9 \\
\hline Bilateral white opacity & & 0.6 \\
\hline Unilateral yellowish opacity & & 0.6 \\
\hline Bilateral yellowish opacity & & 0.7 \\
\hline Unilateral yellowish opacity + LS* & & 0.5 \\
\hline Bilateral yellowish opacity + LS* & & 0.5 \\
\hline
\end{tabular}

Table 4 shows the mean positive social judgment scores according to the individual's perception of the different enamel opacities. Observe that the enamel opacity factor had an effect on all positive characteristics evaluated $(p<0.001)$. These results indicate that all the opacities negatively influenced the judgment of the positive characteristics evaluated, compared to the control $(\mathrm{p}<0.001)$. In general, when the unilateral white opacity was at issue, the total scores for the positive characteristic had the lowest reduction $(\mathrm{p}<0.001)$, whereas the yellow opacity with loss of tooth structure had the highest reduction in the general score $(p<0.001)$.

Table 5 shows the mean scores of the negative social judgments for the enamel opacities. Observe that the enamel opacity factor had an effect on all the negative characteristics evaluated $(p<0.001)$. The results indicate that all the opacities worsened the judgment of the negative characteristics. Bilateral yellowish opacity with or without loss of structure had the greatest impact on this score.

Figure 3 shows the social judgments for the different types of opacities. The results indicate that all the opacities had a negative influence on the participants' perceptions $(p<0.001)$. Unilateral white opacity had the least negative impact on perception, whereas unilateral yellowish opacity and bilateral yellowish opacity with or without loss of structure had the most negative impact.

Figure 4 shows the beauty score $(p<0.001)$. The opacity that negatively affected aesthetic perception the most was bilateral yellowish opacity with or without loss of structure.

\section{Discussion}

The literature has shown an increase in the number of individuals with DDE in the last 10 years, together with major consequences to aesthetic perception. 
Table 4. Scores (mean \pm standard deviation and median \pm interquartile range) for positive social judgment according to the individual's perception of enamel opacities.

\begin{tabular}{|c|c|c|c|c|c|c|c|c|}
\hline \multirow[b]{2}{*}{ Characteristics } & \multicolumn{7}{|c|}{ Enamel Opacities } & \multirow[b]{2}{*}{ p-valor* } \\
\hline & Control & $\begin{array}{c}\text { Unilateral } \\
\text { white opacity }\end{array}$ & $\begin{array}{c}\text { Bilateral } \\
\text { white opacity }\end{array}$ & $\begin{array}{l}\text { Unilateral } \\
\text { yellowish } \\
\text { opacity }\end{array}$ & $\begin{array}{l}\text { Bilateral } \\
\text { yellowish } \\
\text { opacity }\end{array}$ & $\begin{array}{l}\text { Unilateral } \\
\text { yellowish } \\
\text { opacity } \\
+ \text { ELS** }\end{array}$ & $\begin{array}{c}\text { Bilateral } \\
\text { yellowish } \\
\text { opacity + } \\
\text { ELS** }\end{array}$ & \\
\hline $\begin{array}{l}\text { Do you find this } \\
\text { boy/girl funny? }\end{array}$ & $2.52 \pm 0.54^{a}$ & $2.05 \pm 0.59^{b}$ & $1.80 \pm 0.73^{c d}$ & $1.95 \pm 0.59 \mathrm{bc}$ & $1.65 \pm 0.70^{d}$ & $1.85 \pm 0.53^{\mathrm{bcd}}$ & $1.55 \pm 0.70^{d}$ & $<0.001$ \\
\hline $\begin{array}{l}\text { Do you find this } \\
\text { boy/girl happy? }\end{array}$ & $2.45 \pm 0.54^{a}$ & $1.95 \pm 0.58^{b}$ & $1.72 \pm 0.70^{\text {bc }}$ & $1.87 \pm 0.57 \mathrm{bc}$ & $1.64 \pm 0.64^{c}$ & $1.77 \pm 0.60^{\mathrm{bc}}$ & $1.55 \pm 0.61^{c}$ & $<0.001$ \\
\hline $\begin{array}{l}\text { Do you find that this boy/or } \\
\text { girl has many friends? }\end{array}$ & $2.50 \pm 0.54^{a}$ & $2.03 \pm 0.58^{b}$ & $1.78 \pm 0.71^{\mathrm{bcd}}$ & $1.91 \pm 0.64^{\mathrm{bc}}$ & $1.67 \pm 0.67^{c d}$ & $1.82 \pm 0.65^{\mathrm{bcd}}$ & $1.56 \pm 0.61^{\mathrm{d}}$ & $<0.001$ \\
\hline $\begin{array}{l}\text { Would you like this boy/girl } \\
\text { to be your friend? }\end{array}$ & $2.54 \pm 0.54^{a}$ & $2.07 \pm 0.59^{b}$ & $1.83 \pm 0.71^{b c}$ & $1.96 \pm 0.58^{b c}$ & $1.71 \pm 0.72^{c}$ & $1.86 \pm 0.62^{\mathrm{bc}}$ & $1.62 \pm 0.69 c$ & $<0.001$ \\
\hline $\begin{array}{l}\text { Do you think this boy/girl is } \\
\text { intelligent? }\end{array}$ & $2.48 \pm 0.54^{a}$ & $2.01 \pm 0.57^{b}$ & $1.76 \pm 0.70^{\mathrm{bcd}}$ & $1.90 \pm 0.60^{b c}$ & $1.65 \pm 0.66^{\mathrm{cd}}$ & $1.79 \pm 0.61^{\mathrm{bcd}}$ & $1.55 \pm 0.76^{d}$ & $<0.001$ \\
\hline $\begin{array}{l}\text { Do you think this boy/girl is } \\
\text { handsome? }\end{array}$ & $2.48 \pm 0.54^{\circ}$ & $2.01 \pm 0.59^{b}$ & $1.76 \pm 0.68^{\mathrm{bcd}}$ & $1.91 \pm 0.61^{\mathrm{bc}}$ & $1.61 \pm 0.65^{\mathrm{cd}}$ & $1.80 \pm 0.66^{\mathrm{bcd}}$ & $1.48 \pm 0.72^{\mathrm{d}}$ & $<0.001$ \\
\hline Total GSC & $14.97 \pm 3.00^{a}$ & $12.11 \pm 3.28^{b}$ & $10.65 \pm 4.06^{\mathrm{ce}}$ & $11.49 \pm 2.99^{c}$ & $9.93 \pm 3.35^{d}$ & $10.88 \pm 2.82^{\mathrm{e}}$ & $9.31 \pm 3.02^{f}$ & $<0.001$ \\
\hline
\end{tabular}

GSC: good social characteristics; *Friedman test (different $a, b, c, d$, e, fletters in rows indicate statistical difference in opacity change according to the Wilcoxon test); **ELS: Enamel with loss of structure.

Table 5. Scores (mean \pm standard deviation and median \pm interquartile range) for negative social judgment according to the individual's perception of enamel opacities.

\begin{tabular}{|c|c|c|c|c|c|c|c|c|}
\hline \multirow[b]{2}{*}{ Characteristics } & \multicolumn{7}{|c|}{ Enamel Opacities } & \multirow[b]{2}{*}{ p-valor* } \\
\hline & Control & $\begin{array}{c}\text { Unilateral } \\
\text { white opacity }\end{array}$ & $\begin{array}{c}\text { Bilateral } \\
\text { white opacity }\end{array}$ & $\begin{array}{l}\text { Unilateral } \\
\text { yellowish } \\
\text { opacity }\end{array}$ & $\begin{array}{l}\text { Bilateral } \\
\text { Yellowish } \\
\text { opacity }\end{array}$ & $\begin{array}{l}\text { Unilateral } \\
\text { yellowish } \\
\text { opacity } \\
+ \text { ELS** }^{*}\end{array}$ & $\begin{array}{l}\text { Bilateral } \\
\text { yellowish } \\
\text { opacity }+ \\
\text { ELS** }\end{array}$ & \\
\hline $\begin{array}{l}\text { Do you think this boy/girl } \\
\text { is ashamed? }\end{array}$ & $-0.83 \pm 0.60^{a}$ & $-1.40 \pm 0.64^{b}$ & $-2.00 \pm 0.62^{c}$ & $-1.73 \pm 0.68^{b}$ & $-2.15 \pm 0.63^{c}$ & $-1.75 \pm 0.71^{b}$ & $-2.24 \pm 0.57^{c}$ & $<0.001$ \\
\hline $\begin{array}{l}\text { Do you think this boy/girl } \\
\text { likes to be alone? }\end{array}$ & $-0.77 \pm 0.57^{a}$ & $-1.27 \pm 0.49^{b}$ & $-1.85 \pm 0.67^{c}$ & $-1.38 \pm 0.49^{\mathrm{bd}}$ & $-1.72 \pm 0.75^{c d}$ & $-1.27 \pm 0.49^{b}$ & $-1.85 \pm 0.67 c$ & $<0.001$ \\
\hline $\begin{array}{l}\text { Do you think this boy/girl } \\
\text { could start fights? }\end{array}$ & $-0.80 \pm 0.57^{a}$ & $-1.68 \pm 0.64^{b}$ & $-1.96 \pm 0.68^{b c}$ & $-1.98 \pm 0.65^{b c}$ & $-2.15 \pm 0.85^{c}$ & $-2.06 \pm 0.76^{b c}$ & $-2.22 \pm 0.76^{c}$ & $<0.001$ \\
\hline $\begin{array}{l}\text { Do you think that } \\
\text { classmates of this } \\
\text { boy/girl put nicknames } \\
\text { on him/her? }\end{array}$ & $-0.82 \pm 0.56^{a}$ & $-1.72 \pm 0.68^{b}$ & $-2.02 \pm 0.70^{b c}$ & $-2.12 \pm 0.67 c$ & $-2.25 \pm 0.83^{c}$ & $-2.20 \pm 0.71^{c}$ & $-2.31 \pm 0.75^{c}$ & $<0.001$ \\
\hline $\begin{array}{l}\text { Do you think this boy/girl } \\
\text { should be ashamed to } \\
\text { smile? }\end{array}$ & $-0.79 \pm 0.56^{a}$ & $-2.08 \pm 0.52^{b}$ & $-2.49 \pm 0.67^{c d}$ & $-2.48 \pm 0.63^{c d}$ & $-2.61 \pm 0.70^{c d}$ & $-2.37 \pm 0.66^{b d}$ & $-2.72 \pm 0.59 c$ & $<0.001$ \\
\hline $\begin{array}{l}\text { Do you think this } \\
\text { boy/girl needs to look } \\
\text { for a dentist? }\end{array}$ & $-0.51 \pm 0.52^{a}$ & $-2.47 \pm 0.42^{b}$ & $-2.62 \pm 0.57^{b c d}$ & $-2.62 \pm 0.58^{b c}$ & $-2.81 \pm 0.49^{c d}$ & $-2.77 \pm 0.45^{\mathrm{cd}}$ & $-2.91 \pm 0.35^{d}$ & $<0.001$ \\
\hline Total ${ }^{* * *}$ BSC & $-4.52 \pm 2.83^{a}$ & $-10.60 \pm 2.74^{b}$ & $-12.94 \pm 2.97^{c}$ & $-12.30 \pm 2.31^{c e}$ & $13.69 \pm 2.90^{d f}$ & $12.40 \pm 2.2$ & $-14.25 \pm 2.28^{f}$ & $<0.001$ \\
\hline
\end{tabular}

*Friedman test (different $a, b, c, d, e, f$ letters in rows indicate statistical difference in opacity change according to the Wilcoxon test); ${ }^{* *} E L S:$

Enamel with loss of structure. ${ }^{* * *}$ BSC: Bad social characteristics

This perception toward dental enamel may have a significant impact on the physical, social, and psychological well-being of individuals, and may also affect their families..$^{21,22}$
A white smile is highly valued in society, especially in the age group of adolescents and young adults. In the present study, all the enamel opacities were found to have a negative impact on the perception of 


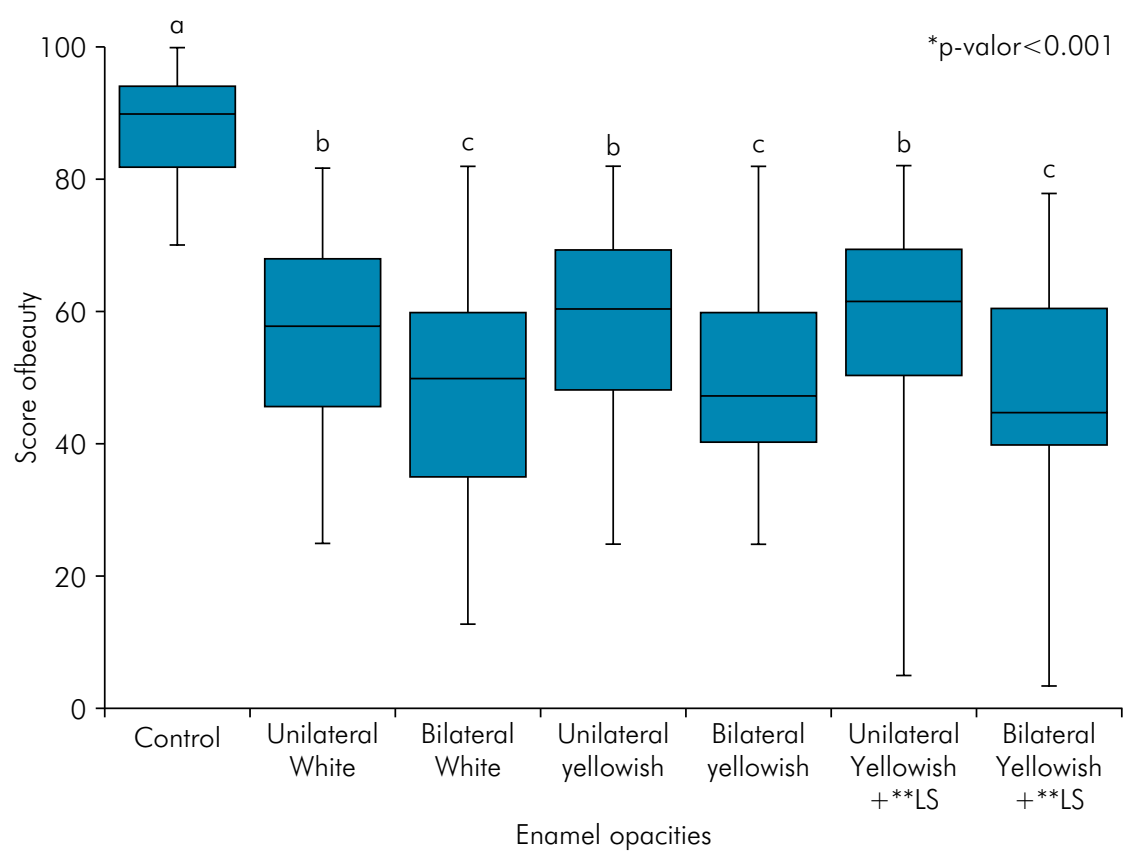

Figure 3. Social judgment score according to the enamel opacities. Rectangle height represents quartiles 1 and 3 ; line cutting the rectangle represents the median; the semi-quarters connect quartiles 1 and 3 to the minimum and maximum values. ${ }^{*}$ Friedman test (different $a, b, c, d, e, f$ letters in rows indicate the statistical difference in opacity change according to the Wilcoxon test); ** Opacities with loss of structure

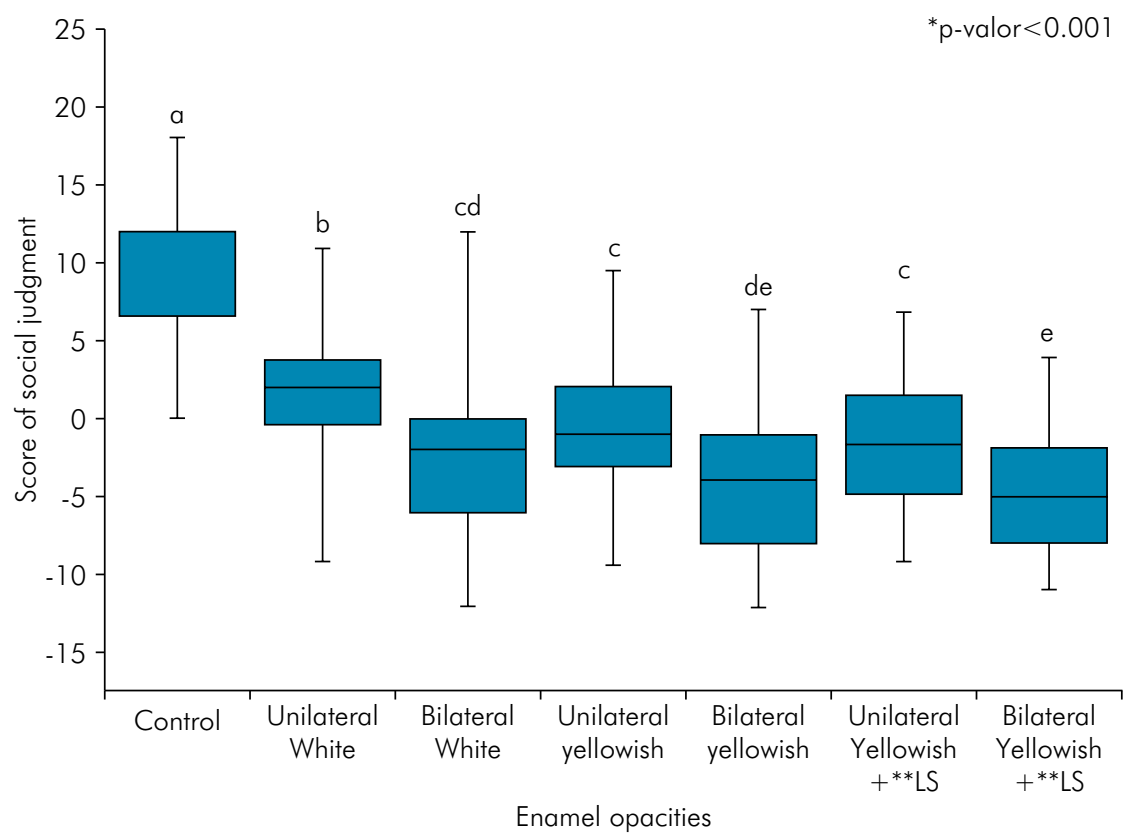

Figure 4. Beauty score according to enamel opacities. Rectangle height represents quartiles 1 and 3 ; the line that cuts the rectangle represents the median; the semi-quarters connect quartiles 1 and 3 to the minimum and maximum values. *Friedman test (different $a, b, c$, $d, e, f$ letters in rows indicate the statistical difference in opacity change according to the Wilcoxon test); ${ }^{* *}$ Opacities with loss of structure.

the adolescents, and influenced their negative social judgments. This result corroborates those of other studies using similar methodologies. It shows that adolescents have a harsh perception of appearance and 
may make value judgments about other people, based on aesthetic imperfections related to stained teeth., ${ }^{2,20,23}$

Adolescence is a transitional stage of physical, psychological and social interaction and human development. The perceptions of others can influence the way a person acts, and can even result in long-term developmental changes. ${ }^{20}$ The number of individuals who fall victim to bullying or prejudgment regarding their appearance has been rising. ${ }^{24}$ Children and adolescents affected by bullying or any type of prejudgment due to physical traits may become adults with low self-esteem, have relationship problems, and/or have a high chance of exhibiting aggressive behavior. ${ }^{24}$

Tooth color plays a crucial role in social development. Furthermore, it is perceived as critical in regard to satisfaction with one's smile appearance. The noticeable discoloration of teeth can have a detrimental impact on a person's physical attractiveness, self-image, and self-confidence. Studies of individuals with DDE are important to understand how much this affects people's perceptions. ${ }^{13,25,26}$ Most studies corroborate that DDE causes loss of tooth structure, resulting not only in aesthetic but also functional problems (sensitivity and dental caries $)^{18}$ for the individual, to the point of affecting quality of life. It is very important that professionals understand how very dissatisfied patients are with enamel defects, in addition to how these individuals are seen by other people.

In addition, it is important that DDE be diagnosed correctly to guide dentists toward developing the most appropriate treatment, considering that one of the great difficulties encountered is the treatment choice for teeth affected by DDE. The following factors should be borne in mind before indicating the treatment: the stage of eruption, the affected tooth, the severity of the DDE and the patient's age. ${ }^{23}$ Most treatments have functional complications, ${ }^{23}$ and aesthetic restorations have posed a great challenge to dentists trying to repair enamel defects in the anterior teeth. This is because it is difficult to choose the best restorative treatment for areas with opacity. In the present study, the authors showed readers that there was a negative perception of an opacity, even if it was white. This means that dentists should hear out a patient, even though there may be no indication of a functional restorative treatment that will ensure aesthetic satisfaction.

Among the limitations facing the authors of this study was the use of images to portray social judgment, a practice that can be seen as artificial. In real life, people make judgments about other aspects, such as hair color, height, facial expressions and even voice. However, the images used eliminated any oral condition (dental caries, malocclusion), and focused solely on opacities, thus excluding any bias at the time of perception. Another limitation is that the applied questionnaire did not include sociodemographic characteristics, given that the children's response to these factors would not be reliable. Previous studies reported that aspects related to the skin color and face of individuals influenced social judgment and attractiveness..$^{27,28,29}$ The lack of these aspects could be considered a limitation of the present study, since facial characteristics were not related, and standard clear skin was pictured. The authors of the present study encourage future studies to assess these aspects, and the influence of sociodemographic differences on different dental changes.

This study demonstrates that adolescents know that enamel defects and even opacities without loss of structure negatively affect the perception of individuals. The authors suggest that other studies be undertaken to determine the aesthetic perceptions of patients with DDE at different ages and with different socioeconomic conditions. Future studies should also address the actual need for aesthetic treatment in patients with DDE affecting incisors without a loss of structure. Studies on aesthetic appearance are important to evaluate the real need for treatment, especially in young patients whose aesthetic demands are high.

\section{Conclusion}

Summary defects in tooth enamel may negatively affect an individual's social life. In this study, even opacities without any structural loss were found to negatively affect an individual's perception. Yellowish opacities with loss of tooth structure had a very negative influence on an individual's perception and social judgment. 


\section{Acknowledgement}

This study was funded in part by the Coordenação de Aperfeiçoamento Pessoal de Nivel Superior Brasil
(CAPES) - Funding code 001, and Fundação Amparo à Pesquisa do Estado do Rio de Janeiro, Brasil (FAPERJ), grant number E-26/201.745/2019.

\section{References}

1. Rossini G, Parrini S, Castroflorio T, Fortini A, Deregibus A, Debernardi CL. Children's perceptions of smile esthetics and their influence on social judgment. Angle Orthod. 2016 Nov;86(6):1050-5. https://doi.org/10.2319/102715-722

2. Craig SA, Baker SR, Rodd HD. How do children view other children who have visible enamel defects? Int J Paediatr Dent. 2015 Nov;25(6):399-408. https://doi.org/10.1111/ipd.121463.

3. Fédération Dentaire Internationale Working Group. A review of developmental defects of the enamel dental index (DDE Index). Commission on Oral Health, Research \& Epidemiology. Int Dent J. 1992;42(6):411-26.

4. Chauhan D, Chauhan T. Prevalence of developmental defects of enamel in mixed and permanent dentition of 9 and 12 year old children of Himachal Pradesh, India: A cross sectional study. Int J Health Allied Sci. 2013;2(3):185-8. https://doi.org/10.4103/2278-344X.120587

5. Robles MJ, Ruiz M, Bravo-Perez M, González E, Peñalver MA. Prevalence of enamel defects in primary and permanent teeth in a group of schoolchildren from Granada (Spain). Med Oral Patol Oral Cir Bucal. 2013 Mar;18(2):e187-93. https://doi.org/10.4317/medoral.18580

6. Gisoo FF, Mohseni A. Prevalence study of etiologies of developmental defects of enamel of first permanent molar among six to seven years old children. Curr Res Dent. 2010;1(2):19-22. https://doi.org/10.3844/crdsp.2010.19.22

7. Laisi S, Ess A, Sahlberg C, Arvio P, Lukinmaa PL, Alaluusua S. Amoxicillin may cause molar incisor hypomineralization. J Dent Res. 2009;88(2):132-6. https://doi.org/10.1177/0022034508328334

8. Alaluusua S. Aetiology of molar-incisor hypomineralisation: a systematic review. Eur Arch Paediatr Dent. 2010 Apr;11(2):53-8. https://doi.org/10.1007/BF03262713

9. Jeremias F, Koruyucu M, Küchler EC, Bayram M, Tuna EB, Deeley K, et al. Genes expressed in dental enamel development are associated with molar-incisor hypomineralization. Arch Oral Biol. 2013 Oct;58(10):1434-42. https://doi.org/10.1016/i.archoralbio.2013.05.005

10. Chawla N, Messer LB, Silva M. Clinical studies on molar-incisor-hypomineralisation part 2: development of a severity index. Eur Arch Paediatr Dent. 2008 Dec;9(4):191-9. https://doi.org/10.1007/BF03262635

11. Rodd HD, Abdul-Karim A, Yesudian G, O'Mahony J, Marshman Z. Seeking children's perspectives in the management of visible enamel defects. Int J Paediatr Dent. 2011 Mar;21(2):89-95. https://doi.org/10.1111/j.1365-263X.2010.01096.x

12. Feng XP, Newton JT, Robinson PG. The impact of dental appearance on perceptions of personal characteristics among Chinese people in the United Kingdom. Int Dent J. 2001 Aug;51(4):282-6. https://doi.org/10.1002/j.1875-595X.2001.tb00839.x

13. Meneghim MC, Kozlowski FC, Pereira AC, Assaf AV, Tagliaferro EP. Perception of dental fluorosis and other oral health disorders by 12-year-old Brazilian children. Int J Paediatr Dent. 2007 May;17(3):205-10. https://doi.org/10.1111/j.1365-263X.2006.00821.x

14. Brehmer B. Social judgment theory and the analysis of interpersonal conflict. Psychol Bull. 1976;83(6):985-1003. https://doi.org/10.1037/0033-2909.83.6.985

15. Henson ST, Lindauer SJ, Gardner WG, Shroff B, Tufekci E, Best AM. Influence of dental esthetics on social perceptions of adolescents judged by peers. Am J Orthod Dentofacial Orthop. 2011 Sep;140(3):389-95. https://doi.org/10.1016/i.ajodo.2010.07.026

16. Magno MB, de Paiva Cabral Tristão SK, Jural LA, Aguiar Sales Lima SO, Coqueiro RD, Maia LC, et al. Does dental trauma influence the social judgment and motivation to seek dental treatment by children and adolescents? Development, validation, and application of an instrument for the evaluation of traumatic dental injuries and their consequences. Int J Paediatr Dent. 2019 Jul;29(4):474-88. https://doi.org/10.1111/ipd.12479

17. Harter S. Is self-esteem only skin-deep? The inextricable link between physical appearance and self-esteem. Reclaiming Child Youth. 2000;9:133-8.

18. Ozgül BM, Saat S, Sönmez H, Oz FT. Clinical evaluation of desensitizing treatment for incisor teeth affected by molar-incisor hypomineralization. J Clin Pediatr Dent. 2013;38(2):101-5. https://doi.org/10.17796/jcpd.38.2.92m×26l6n482j682

19. Coluci MZ, Alexandre NM, Milani D. [Construction of measurement instruments in the area of health]. Cien Saude Colet. 2015 Mar; 20(3):925-36. Portuguese. https://doi.org/10.1590/1413 81232015203.04332013

20. Prokhorov AV, Perry CL, Kelder SH, Klepp KI. Lifestyle values of adolescents: results from Minnesota Heart Health Youth Program. Adolescence. 1993;28(111):637-47.

21. Sujak SL, Abdul Kadir R, Dom TN. Esthetic perception and psychosocial impact of developmental enamel defects among Malaysian adolescents. J Oral Sci. 2004 Dec;46(4):221-6. https://doi.org/10.2334/josnusd.46.221 
22. Kavand G, Broffitt B, Levy SM, Warren JJ. Comparison of dental esthetic perceptions of young adolescents and their parents. J Public Health Dent. 2012;72(2):164-71. https://doi.org/10.1111/j.1752-7325.2011.00306.x

23. Ghanim AM, Manton DJ, Morgan MV, Mariño RJ, Bailey DL. Trends of oral health care and dental treatment needs in relation to molar incisor hypomineralisation defects: a study amongst a group of Iraqi schoolchildren. Eur Arch Paediatr Dent. 2012 Aug;13(4):171-8. https://doi.org/10.1007/BF03262866

24. Serra-Negra JM, Paiva SM, Bendo CB, Fulgêncio LB, Lage CF, Corrêa-Faria P, et al. Verbal school bullying and life satisfaction among Brazilian adolescents: profiles of the aggressor and the victim. Compr Psychiatry. 2015 Feb;57:1329. https://doi.org/10.1016/i.comppsych.2014.11.004

25. Simmer JP, Hu JC. Dental enamel formation and its impact on clinical dentistry. J Dent Educ. 2001 Sep;65(9):896-905.

26. Leal SC, Oliveira TR, Ribeiro AP. Do parents and children perceive molar-incisor hypomineralization as an oral health problem? Int J Paediatr Dent. 2017 Sep;27(5):372-9. https://doi.org/10.1111/ipd.12271

27. Vera Cruz G. The impact of face skin tone on perceived facial attractiveness: A study realized with an innovative methodology. J Soc Psychol. 2018;158(5):580-90. https://doi.org/10.1080/00224545.2017.1419161

28. Vera Cruz G. The Impact of Face Skin Tone vs. Face Symmetry on Perceived Facial Attractiveness. J Gen Psychol. 2018 AprJun;145(2):183-98. https://doi.org/10.1080/00221309.2018.1459452

29. Lima TJ, Pereira CR, Torres ARR, Souza LEC, Albuquerque IM. Black people are convicted more for being black than for being poor: the role of social norms and cultural prejudice on biased racial judgments. PLoS One. 2019 Sep;14(9):e0222874. https://doi.org/10.1371/journal.pone.0222874 